\title{
Fast Times in Hallowed Halls: Making Time for Activism in a Culture of Speed
}

\author{
KAMILLA PETRICK \\ Lakehead University, Canada
}

\begin{abstract}
This article examines the implications of the social acceleration of time for the capacity of activist-scholars to engage in collective action. Drawing on interdisciplinary literature on time and temporality, the article argues that the neoliberal university is driven by the same speed imperative that underpins the capitalist mode of production, and that the resulting and growing time pressures inhibit academics' (and others') involvement in social movements in profound and deleterious ways. To explore this argument empirically, I draw on insights gleaned from semi-structured interviews with Canadian activist-scholars. Despite the manifest diversity of temporal experiences and challenges faced by scholar-activists in contemporary high-speed society, it is clear that academics today face severe time pressures that apply across individual differences and across disciplines. These pressures, which can only be properly explicated with reference to the ruling politicaleconomic paradigm, militate against the capacity to engage in reflexive thought (for both scholarly and activist purposes) and also against a higher level of involvement of 'public intellectuals' in social movements. The article's conclusion offers a few tentative thoughts about tempering the speed imperative for the purpose of self-care and by extension, for the common good in the long run.
\end{abstract}

KEYWORDS social acceleration; time; neoliberal university; social movements; collective action; activist-scholars

"Extreme busyness" (Scheuerman, 2005, p. 449) - or, to use the language of social movement studies, the shortage of time as a resource of collective action - is frequently proffered by self-identified progressives, including scholars, as a major reason for their lack of more active involvement in social activism. Although it may now be widely accepted as a given, the widespread condition of acute time scarcity has a profound impact upon the character and extent of academics' (and others') social movement participation. Without wanting to diminish the contribution of individual 
activist engagements, in this article I focus on the importance of collective action as constitutive of social movements, classically defined (i.e., Tilly, 2004). I contend that, insofar as action taken in tandem with civil society actors at large constitutes a vital and integral element of the academic vocation, the impact of social acceleration on academics' civic engagement needs to be (re)examined critically and made strange again, so that we might become better equipped to resist the pervasive "culture of speed" (Tomlinson, 2007, p. 8) and the related pernicious productivity paradigm that plagues both activism and academia.

The article utilizes three main sets of research sources. It proceeds by first drawing on the insights of a growing interdisciplinary body of literature concerning the process of so-called social acceleration, and its impact and implications for activism, as well as for the university as an enterprise. Second, my analysis is informed by a broader project investigating the impact of social acceleration on the temporal tendencies and orientations of 'new media activism.' This project was based on over 70 semi-structured interviews I conducted (primarily in 2011), with leading organizers affiliated with the Canadian alter-globalization movement. Finally, given the article's specific focus on politically engaged academics and the intersectional experience of time and acceleration from their vantage point, supplementary semi-structured interviews with Canadian scholar-activists were carried out between December 2014 and February 2015, and constitute the main material upon which the latter, more substantive, half of this article is based.

In this latter section, I identify and discuss several themes that emerged over the course of the interviews that have shaped individual academics' trajectories of activist involvement. I focus in particular on the specific temporal structure of academic work, the crucial matter of cycles (of life, movements, and the academic year), the important question of academic hierarchy and rank, as well as the role of various biographical factors, identity, and social ties. Despite the manifest diversity of temporal experiences and challenges faced by scholar-activists in contemporary highspeed society, the respondents' answers confirmed that academics today face tremendous time pressures that apply across individual differences and across disciplines. These pressures, which can only be properly explicated with reference to the ruling political-economic paradigm that operates both on and off campus, militate against the capacity to engage in reflexive thought (for both scholarly and activist purposes) and also against involvement by public intellectuals in social movements.

\section{Capitalism and the Speed Imperative}

Social scientists have long recognized that the sense of time and space as experienced by human beings is largely a social construction. Thus, temporal orientations - that is, the relative cultural value placed on different 
dimensions of time: the past, present, and future - are also historically and culturally contingent (Hall, 1983; Levine, 1997). Historically, pre-modern societies were ruled by a cyclical view of time, as shaped and dictated by natural rhythms (day/night, harvest times, etc.), as well as by a cultural emphasis on the past and tradition (Rifkin, 1987; Nowotny, 1994). This temporal outlook changed with the rise of the modern capitalist era and the Enlightenment, which served to eventually displace the tradition-bound, hegemonic past orientation with a future outlook based on a strong faith in social progress. Technological developments, together with the onset of industrialization and Taylorism, further displaced the focus on natural cycles by ushering in a new hegemonic temporality predicated on the growing need for more precise time measurement and scheduling - what scholars have termed the ascent of "clock-time" (Adam, 1995; Reith, 2004; Porter \& Stockdale, 2015). Beginning in the $20^{\text {th }}$ century, the dominant temporal orientation (at least in post-modern societies penetrated by instantaneous communication technologies) started to shift yet again, away from clock-time and increasingly toward what Robert Hassan has termed "network time," a powerful new temporal order predicated on instant and constant connectivity, and spurred on by the nexus between neoliberal globalization and the penetration of daily life by time-compressing communication technologies (Hassan, 2003, 2009).

German sociologist Hartmut Rosa conceptualizes shifts in the hegemonic temporal orientation as stemming from a process that he calls "social acceleration" (see Rosa, 2003, 2005, 2013). According to Rosa, social acceleration is the fundamental process of modernity, which takes three analytically-separable forms: technological innovation, the rate of change, and the pace of life. He further identifies three motors as responsible for driving this complex process: cultural, structural, and economic. Among them, he sees the latter, specifically capitalism, as the "most obvious source of social acceleration" (2009, p. 91). This argument is supported by a swelling body of research on the link between social acceleration and the basic dynamics of capitalism involving competition, and the need to commodify (labour) time and to accelerate the turnover time of capital (e.g., Adam, 1995; Agger, 2004; Harvey, 1989; Eriksen, 2001; Postone, 1993; Manzerolle \& Kjøsen, 2012; Martineau, 2015).

Although workers initially resisted the capitalist speed imperative inside the workplace, as documented by E.P. Thompson in his seminal 1967 essay "Time, Work-Discipline, and Industrial Capitalism," following the so-called 'post-war compromise' between employers and the labour movement, the working class largely abandoned the fight for more free time in exchange for higher wages and improved purchasing power (Hunnicut, 2013). The amount of available leisure time seems to have shrunk substantially since then, yielding what Linder (1970) famously termed The Harried Leisure Class (see also Schor, 1991). Bolstered by the hegemonic culture of speed in which busyness has come to be widely equated with social status and importance 
(and is accordingly often seen as a badge of honour of sorts), today the tendency for work time to colonize leisure time continues unabated. It is particularly strong among 'knowledge workers' - as noted recently by The Economist, with a nod to Linder:

For the past 20 years, and bucking previous trends, the workers who are now working the longest hours and juggling the most responsibilities at home also happen to be among the best educated and best paid. The so-called leisure class has never been more harried. (The Economist, 2014)

It seems safe to assume that this predicament applies in full force to the academic class; indeed, a growing number of empirical studies attest to the intensification of work in the academic sector (e.g., Schuurman, 2009; Jacobs $\&$ Winslow, 2004), which has given rise to a greater sense of an increased pace of life and time pressure among academics.

\section{'Fast Academia': The Speed Imperative Inside the University}

To properly understand the ever-increasing demands of academic life, it is necessary to grasp the basic dynamics that are driving the degradation of the university into a 'knowledge factory' oriented toward ever-faster output. As has been by now well-documented by alarmed scholars (e.g., Readings, 1996; Hearn and Hanke, 2012; Slaughter and Rhoades, 2004; Shantz and Vance, 2000), the process that Slaughter and Leslie (1997) have famously termed "academic capitalism" began in the 1970s, and has proceeded apace since then. It has imbued with the "entrepreneurial spirit" the ranks of administrators keen to enact "new public management" in order to boost "accountability, efficiency, productivity, quality control and costeffectiveness at all levels of academia" (Ylijoki, 2013, p. 242). Commonly referred to as the neoliberal restructuring of the university, this process has entailed drastic cutbacks to funding for post-secondary education, and a correspondingly higher financial dependency of universities on the private sector and tuition fees. The university has consequently shifted away from serving the community as a collegially governed public institution, moving instead toward corporate-managerial approaches to decision-making and efficiency involving increased administrative burdens on professors and an overarching imperative toward accelerated knowledge production.

The institutional pressure to accelerate one's academic 'output' is a common target of critical accounts addressing the university's neoliberal restructuring in the contemporary era. From a temporal perspective, one of the most commonly lamented casualties of this development is what Ylijoki and Mantyla (2003) termed "timeless time," namely the time in which academics feel they can slow down enough to engage in truly critical and creative thought required to produce high quality scholarship. In interviewing 
Canadian academics, Menzies and Newson $(2007,2008)$ discovered a widely shared criticism of the disturbing tendencies to which academics themselves were contributing: "the drift toward shorter, more superficial and taskoriented engagement with colleagues and a subtle shift toward producing knowledge rather than engaging in the kind of reflection and critical dialogue traditionally associated with creating truly original knowledge" (2008, p. 518; see also Levy, 2007; Vostal, 2015). The authors' interview research also substantiated with empirical evidence an argument advanced by a handful of interdisciplinary scholars (e.g., Harvey, 1989; Hassan, 2003, 2009): that there exists a significant dialectical dynamic between evolving communication technologies and shifting temporal norms and orientations. More specifically, and pertinent for our purposes, Menzies and Newson's investigation confirmed that time-accelerating technologies of communication are at least partly to blame for the increased sense of time pressures experienced by academics, particularly vis-à-vis the expectations of instant responsiveness (from students as well as from administrators). The penetration of daily life by these technologies can thus be understood as exerting a negative impact on the availability of time for reflection, and we might add, for civic engagement.

To be sure, the problem of time scarcity predates digital media, as does the speed imperative itself. It was bemoaned as early as the mid- $20^{\text {th }}$ century by Canadian communication scholar Harold Innis, who warned that Western civilization was becoming dangerously preoccupied with the present and with short-term concerns at the expense of the relatively slow oral tradition and critical dialogue (1951; see also Watson, 2006). But, while the process of social acceleration and the associated sense of speed-up might not be new, the penetration of daily life by instantaneous communication technologies is arguably unprecedented, with troubling implications for the capacity for deep thought and for active citizenship. In a cultural milieu shaped by the nexus between neoliberal globalization and these technologies, social actors (including activists and academics) tend increasingly to espouse a mode of reasoning that Hassan (2009) termed "abbreviated thinking." Insofar as it tends to prioritize short-term, instrumental goals and other 'deliverables,' this myopic mode of reasoning threatens "academic culture and the continuation of the university as a space for critical reflection and creative intellectual endeavour" (Menzies \& Newson, 2008, p. 505).

\section{'Fast Activism'}

In addition to its impact on the quality of scholarship, the hegemonic imperative toward speed has important consequences for the patterns and tendencies of collective action in contemporary society. American political scientist William Scheuerman was among the first to argue that "social acceleration...clashes fundamentally with the temporality of citizenship" 
(2005, p. 457). He highlighted in particular the fundamental tension between the imperatives of high-speed society and the inherently slow pace of democratic decision-making and critical reflection (see also Levy, 2007; Hassan, 2009; Comor, 2006).

This line of critique has thus far been largely speculative and not grounded in an empirical analysis of social activists. In an effort to address this gap in the 'time studies' literature, I set forth to investigate with greater empirical rigour the implications of social acceleration for contemporary activism. To this end, I conducted over 70 in-depth interviews with core organizers of the Canadian alter-globalization movement, including a dozen academics. The alter-globalization movement emerged around the world in the late 1990s in opposition to neoliberalism, corporate power, and unfettered free trade. My goals were systematically to document the history of this movement, and to examine the impact of social acceleration on the alter-globalization movement as the example par excellence of new media activism. I examined activists' temporal practices pertaining to the past (preservation and dissemination of collective memory), as well as to the future (long-term strategic planning), and to durability (building sustained social movement infrastructure). I found that the value of all three practices was generally upheld by the majority of my respondents, yet it largely failed to translate into practice, as "fast activism" tends to prioritize short-term tactics and objectives at the expense of the longue durée (Pietrzyk 2013).

In the discussion that follows, I turn to additional interviews carried out with Canadian scholar-activists in order to provide preliminary insights concerning the factors, challenges, and obstacles that impinge on or variously facilitate their active participation in social movements. Although they also clearly valued the longue durée in both their academic work and their activist endeavours, these scholar-activists too feel the pressure to engage in 'fast' academic and activist work, for the reasons outlined above and explored in more depth below.

\section{The Work-Life Boundary: An Academic Quandary}

The Canadian scholar-activists interviewed for this study are well-recognized and respected for their involvement in social movements; as personal acquaintances and comrades of the author, they were also readily reachable. These six individuals - three men and three women, representing both precariously and securely employed academics - gave generously of their time (between 60 and 90 minutes) and did so within the time-frame of this special issue's production schedule (indeed, the irony was not lost on either side as potential interview subjects apologetically cited a lack of time when politely declining the invitation to participate in this study). Though relatively few in number, these qualitative interviews were in-depth and proved very insightful. They were conducted either by phone or face-to-face, then 
transcribed and inductively coded to reveal several themes. While the limited size of the sample precludes me from making generalizations or drawing empirically robust conclusions about the time experiences of Canadian scholar-activists, the observations articulated below do shine new light on the largely unexplored subject matter, and should be helpful in guiding related inquiries in the future.

A good way to proceed is by acknowledging the distinctive temporal structure of academic work. In a study of Finnish academics and their conceptions of time, Yliyoki (2013) found that as the academic profession is widely regarded as a calling, it becomes harder to demarcate periods of academic work from periods of leisure. The latter appears to be never truly available to academics, who profess that research is a way of life rather than a nine-to-five sentence to be endured. Ylijoki's study revealed that academics did not typically delineate a boundary between work and personal time; instead, they were more concerned with another temporal duality, namely the fault line between productive time and wasted time. While the former is spent researching one's freely chosen interests, the latter referred primarily to time spent in meetings or performing what are seen as relatively mindless administrative duties.

In other words, right from the outset, an attempt to figure out how much free time academics have at their disposal that they could allocate to citizen engagement is fraught with an industry-specific challenge. This challenge was articulated by one of my respondents, who noted that:

For many of us who are academics, we love our work. Some of my friends always argue that almost all of us are borderline autistic or something, we're obsessed with the stuff that interests us... We're always working because we're always thinking about the world and I think that makes it harder for us too. (Individual interview, January 7, 2015)

Likewise, an associate professor of sociology and well-respected activist, pointed out:

The nature of academic work is insidious, and it can take over and colonize all kinds of time because it's not something that can only be performed in a particular place, and the time-bounds of the work are less defined. The very freedom of academia is in some ways what makes it so insidious in terms of taking over your other time. (Individual interview, January 20, 2015)

In short, as the comments above suggest, an inquiry into the temporal experiences of academics cannot ignore the difficulty that academics face in carving out time for civic engagement when the expectations defining of one's profession militate against the very category of 'free time.' 


\section{Of Movement, Life, and Other Cycles}

As the insights gleaned from the interviews made clear, the extent of academics' active involvement in social movements is also alternatively constrained or facilitated by various temporal cycles that intersect and overlap in specific ways. While additional such cycles can likely be identified, in this section I examine the implications of three: the cycles of contention/protest, of life, and of the academic year.

First, what has been variously called the "cycles of contention," or "waves of protest," is a core concept in social movement studies that refers to periods of heightened conflict across the social system, in which tactics diffuse rapidly among groups of activists and new alliances take shape (see Tarrow, 1998; McAdam \& Sewell, 2001). The 1960s, the global justice movement, or the Occupy movement are all good examples of such periods. From our perspective, the cyclical patterning of social protest matters because of the power of ascendant waves of dissent to encourage engagement on the part of those who, for a lack of time or other reasons, remain otherwise largely on the peripheries of social movements. When movement cycles are on the rise, more active participation in them suddenly becomes more appealing. Implicitly suggesting that the lack of time is at least in part a matter of personal perception and priorities, a professor of sociology from Toronto noted that when movements are strong and cycles are on the upswing, people (including academics) who normally do not have the time for activism, make time for it. Regrettably, he added, the progressive Left is quite weak at this point in time (at least in Canada) and thus not very enticing. This means that going to organizing meetings tends to feel like just more work rather than an exciting way of spending one's precious spare time. As his comment made clear, the ups and downs of movements clearly impact the willingness of individuals (both inside and outside academia) to make or find time in which to participate in social movement activism. ${ }^{1}$

Second, life cycles - or to put it in the language of social movement studies, the element of biographical availability - emerged as another vital dimension of time with implications for academics' level of movement involvement. In her recent study of the trajectories of protest participation, Canadian sociologist Catherine Corrigall-Brown (2012) found that marriage and child rearing (especially in the early years) act as significant barriers to movement participation. As Corrigall-Brown and other scholars have noted, parenting in particular is heavily gendered, with female academics reporting a greater sense of time pressure (see Menzies \& Newson, 2008; Wolfinger, 2013), not unlike professional women in society at large (see Wajcman, 2015; Leccardi, 1996; Odih, 2003). Given this situation, if female academics choose

\footnotetext{
${ }^{1}$ There is a problematic quality of self-gratifying, myopic opportunism to this mode of engagement, but it does not diminish the beauty or attraction of an emergent wave of collective action.
} 
to have children, it is likely that many of them will drop out of activism. This "individual abeyance" as Corrigall-Brown has termed it (2012, p. 40), proves to be permanent in some cases and temporary in others. The decision to eventually return into the activist fold is motivated by a host of factors including, but not limited to, the ones discussed in this article. ${ }^{2}$

The age of the scholar-activist in question is not insignificant in this respect insofar as it is indicative of generation, and by extension the individual's exposure to, or experience with, historically specific cycles of contention. This point was articulated by a Toronto-based sociologist, who noted that "it's complicated a little bit because of the interaction between the lifecycle and the ups and downs of movements, so that some of the more active politicos I know in academia are older... simply because we were politicized at a time when movements were more exciting in certain ways, so it got deeper inside us..." (Individual interview, January 20, 2015).

Likewise, a retired professor in a Faculty of Education attested to a big generational divide among scholar-activists. Her own generation of fellow feminist scholars was very actively involved in women's issues in the community, she noted, whereas today the junior faculty in the field seem largely disconnected:

I watch my younger colleagues who often have very good politics in the abstract but who don't enact those politics in their behaviour inside the university. They haven't resisted the university, they haven't exercised agency, they've just really bought into a lot of the rhetoric and the neoliberal bullshit that goes on in universities now and haven't challenged it, and their excuse is, 'well you know they have get these articles out,' because they need to get tenure, and I'm not someone who says 'no, no, don't go for tenure,' but I am someone who thinks that as professors we are supposed to be the governance structure of our university and we've completely let that out of our grasp... (Individual interview, January 7, 2015)

Finally, the third cycle I wish to briefly discuss that shapes and structures academics' involvement in social movements is the cycle of the academic year. As every scholar knows, there are predictable periods of heightened activity in each academic year, during which there is less time available for activism and other activities. This insight was conveyed by a tenured professor of global studies, who noted that his level of activist involvement shrinks and expands in keeping with this cycle: it grows during the summer and shrinks during the fall and winter terms. "Even within the term there's a certain cycle," he added, referring to the months of September and January, during which there is relatively less grading work to be done, allowing for

\footnotetext{
${ }^{2}$ Corrigall-Brown (2012) finds that individuals who have more education and more political knowledge are less likely to disengage permanently from activism and instead follow the abeyance pattern of participation; scholar-activists can be presumed to satisfy both criteria.
} 
greater activist engagement, given the inclination (Individual interview, January 16, 2015) .

In short, as this section has sought to make clear, a multiplicity of temporal cycles carry significant consequences for patterns of collective action among academics; hence any attempt at a holistic, nuanced account of scholaractivists' temporal experiences must consider their intersecting and overlapping character.

\section{Time Pressures and the Academic Hierarchy}

In this section, I turn to the question of academic rank and status and its role in shaping the capacity of academics to become engaged in social movements. Recent scholarship (e.g., Gutiérrez y Muhs \& Niemann, 2012; Müller, 2014; Mendick, 2014) demonstrates that the experience of acute time scarcity depends to a large extent on social status and differentiation, including academic hierarchies. Thus, being a female adjunct professor entails different time pressures than those faced by a male tenured professor, for example. In an influential article about the "conflicting time perspectives in academic work," Oili-Helena Yliyoki and Hans Mantyla (2003) conceptualize "contract time" as the short-termist mode of eking out a living as a 'sessional' faculty member, term by term. Although tenure-track faculty have to subjugate various areas of their lives in keeping with the tyranny of the 'tenure-clock,' contract faculty members endure high levels of uncertainty and precarity as they pursue employment opportunities wherever and whenever they may arise, most often on a temporary basis.

Moreover, to become or remain competitive in the academic labour market, 'sessional lecturers', as they are alternatively dubbed, are confronted with the expectation to engage in research and to publish, just like their tenure-stream counterparts; however, not being part of their job description, research performed by these individuals is not remunerated. Instead, it must be done in their spare time, which is typically next to nil, being consumed by the extra heavy teaching loads necessitated by the low rates of pay afforded contract faculty. As a result, not only do the research agendas of contract faculty tend to suffer, but also their ability to devote time to contentious collective action. As noted by one of the interview respondents:

Often the people going through the system now - because of all those pressures tend to lose the habit of having a self outside of the one that gets consumed by the neoliberal academic institution. And that makes it harder both personally in terms of actually having a personal life, but also politically. (Individual interview, January 20, 2015)

For those lucky enough to have a tenure-track position, tenure does make activist engagement a little easier. A tenured professor of global studies made this point: 
It's a completely different kettle of fish to be tenured because there's so much more freedom, so much less pressure, and so much more capacity to delay completion of a project without immediate, practical consequences. So it's very freeing in that sense. (Individual interview, January 16, 2015)

The pressures on tenured academics at his institution are less than tenuretrack faculty face, but, he added, this too varies from school to school, one presumes in line with the specific expectations set at the departmental and institutional level, including what can sometimes be increased expectations to play a larger administrative role or supervise more students. Although it would be inaccurate to assert that all pressures are lessened, to the extent that the demands on one's time imposed by the tenure clock cause scholaractivists to cease social movement involvement, securing tenure can facilitate a re-engagement by permitting greater temporal autonomy.

The tyranny of the tenure clock is a readily recognized predicament among academics; indeed, anecdotal and empirical interview-based evidence (Ylijoki 2013) shows that some contract faculty perceive a bright side to their precarious predicament, namely a certain freedom from the temporal demands of administrative work placed on their tenure-stream colleagues (again, typically viewed by academics with resentment as a waste of time; see Ylijoki, 2013). This is not a universal condition or sentiment. As noted by one of my precariously employed respondents, contact faculty may face implicit pressure to engage in administrative tasks, stemming from the imperatives of competition and the drive for 'excellence.' As she pointed out, many contract faculty "are actually attending the endless administrative service meetings because they want to be seen and respected and to build their reputation in their department." (Individual interview, December 22, 2014). To the extent that they do so, they have less time for other pursuits, including participation in collective political action.

\section{Making Time for Activism: The Role of Identity and Social Ties}

While the preceding discussion has shed some light on the differential participation of academics in activism, we would be remiss to overlook two additional and important pieces of the puzzle: the role of identity and social ties in shaping academics' trajectories of social movement engagement. Social movement scholars have long recognized the power of collective identity and social ties in motivating contentious collective action (e.g., McAdam, 1988; Downton \& Wehr, 1997). Self-identification as an activist likewise has been found to factor into decisions regarding whether to exit or sustain one's engagement. As noted by Corrigall-Brown (2012), social ties created in voluntary groups make individuals both more likely to participate in forms of collective action and less likely to disengage permanently over time. 
The significance of activist identity and social ties was emphasized emphatically by one of my respondents, a long-time activist and social movement scholar in Toronto. First, she confirmed Corrigall-Brown's insight regarding identity by noting the following:

If you see yourself as an activist, it's a pretty dominant identity (...) How you define yourself really affects the logic with which you decide, well, it's much more important for me to go to that meeting or go to that demonstration than do the research. But then it's really, really hard to get the research done, which is why I don't have a massive research agenda a lot of the time because I don't have time for it. Now I've managed to get tenure regardless [laughs], but I think a lot of people who are very committed to movements still, for sure your academic productivity rate...is going to be lower. (Individual interview, January 8, 2015)

She also underlined the salience of having strong interpersonal connections with other activists as key to remaining engaged. "My relationships are very supportive of activism," she observed with respect to her friendships, housemates, and romantic ties, "and they are much more tied to activism than academia... so when I go through periods of withdrawal from fully engaged activism, I get called on it." Her comments help us better understand why some scholar-activists, when confronted with comparable time pressures attached to the profession, are more inclined to make time for social movement involvement, than some of their like-minded colleagues - and the potential costs of such choice.

\section{Time, Activism and the Long Haul}

As part of the collective enterprise driving this special issue, namely to critically examine in order to transcend the various constraints standing in the way of collective action, this article's aim was to shed light on the vital importance of time as a resource of contentious collective action. Time is a resource perceived to be increasingly scarce and 'at a premium' in today's high-speed society and inside the 'high-speed university' by extension. This pervasive sense of time scarcity is experienced differently depending on individual scholars' circumstances, academic status, gender, and other factors; yet, the sense of aggravated busyness cuts demonstrably across these distinctions, impacting detrimentally the perceived capacity to devote time to political activities 'above and beyond' competing, ostensibly more pressing elements of the academic profession. Additional participant research and analysis is, however, necessary to produce empirically robust insights into social acceleration's impact on scholar-activists. The more modest aim of this article has been to initiate this discussion in a serious way, first of all by shattering the commonsensical character of the condition of extreme busyness that is so widely cited as a central reason for one's lack of active involvement in social movements. 
To be sure, the real and perceived lack of time is far from the only hurdle preventing academics from being more actively involved in social activism. As my respondents observed, in many cases there are more-or-less subtle ways in which a scholar-activist might be penalized for being too politically radical, including unfavourable top-down decisions regarding hiring, promotion, grants, etc. However, a growing body of scholarship, including my research into the temporal tendencies of scholar-activists, suggests strongly that the time pressures experienced by academics today are more powerful than ever in both the objective and subjective sense. This means that academics at all tiers of the academic system find themselves feeling hardpressed to find the time for constitutive activities associated with their vocation, notably research, which might at first blush suggest that their inability to find the time for anything else, including activism, represents merely a logical extension of this condition. At this point it would behoove us to remember that, like research, social activism constitutes an integral element of the academic vocation (at least in the social sciences and the humanities). In the famous words of Karl Marx, "The philosophers have only interpreted the world, in various ways. The point, however, is to change it"(Marx \& Engels, 1969). Indeed, the need for academics to serve the society-at-large as public intellectuals has arguably never been greater, as the world confronts burning, potentially catastrophic problems in urgent need of thoughtful and socially just solutions.

Yet, it will also come as no surprise that there are no simple fixes to the pervasive problem of social acceleration and its negative implications for both critical thinking and active social movement participation. Echoing Vostal (2015) in eschewing simplistic calls for the (unrealistic) return to a slower time, I wish to conclude by harkening back to the aforementioned distinction between a temporary versus permanent abeyance from movement activity. My own experiences as a scholar-activist, borne out by much anecdotal evidence collected over the years, confirm that even the most committed, hard-core activist will experience moments when withdrawal is inevitable and perhaps even necessary, either because of burnout or due to biographical and life-cycle reasons. What matters above all, I would argue, is that the person eventually returns within the fold of social justice activism, because to do otherwise is just not possible. Thankfully, life-long activists are not an uncommon breed, and from them we may draw our inspiration. Notably, the deceased parents of one of my respondents were recently mourned and celebrated in equal measure for their outstanding contributions to social justice. The vital lesson they taught him, my respondent informed me, was the importance of balance and self-care for the long haul, because the revolution is not around the corner (quite yet) (Individual interview, December 22, 2014). This lesson is captured brilliantly in a quotation paraphrased from Bertold Brecht, which was invoked at my participant's father's funeral, in loving recognition of his and his spouse's life-long commitment to activism: 
There are those who struggle for a day and they are good.

There are those who struggle for a year and they are better.

There are those who struggle many years, and they are better still.

But there are those who struggle all their lives: these are the indispensable ones.

(Brecht, paraphrased in Reynolds, 1997, p. v)

\section{References}

Adam, B. (1995). Timewatch. Cambridge: Polity Press.

Agger, B. (2004). Speeding up fast capitalism: Cultures, jobs, families, schools, bodies. Boulder, CO: Paradigm Publishing.

Comor, E. (2006). Neo-imperialism and the crisis of time. TOPIA: Canadian Journal of Cultural Studies, 10, 1-21.

Corrigall-Brown, C. (2012). Patterns of protest: Trajectories of participation in social movements. Stanford, CA: Stanford University Press.

Downton, J. Jr., \& Wehr, P. (1997). The persistent activist: How peace commitment develops and survives. Boulder, CO: Westview Press.

Eriksen, T. (2001). Tyranny of the moment: Fast and slow times in the information age. London: Pluto Press.

Gutiérrez y Muhs, G., \& Niemann, Y. F. (2012). Presumed incompetent: The intersections of race and class for women in the academy. Boulder: University of Colorado Press.

Hall, E. T. (1983). Dance of life: The other dimension of time. Garden City, NY: Anchor/Doubleday.

Harvey, D. (1989). The condition of postmodernity: An enquiry into the origins of cultural change. Oxford: Blackwell.

Hassan, R. (2003). The chronoscopic society: Globalization, time and knowledge in the network economy. New York: Peter Lang.

Hassan, R. (2009). Empires of speed: Time and the acceleration of politics and society. Lieden: Brill.

Hearn, A., \& Hanke, B. (2012). Introduction: Out of the ruins, the university to come. TOPIA: Canadian Journal of Cultural Studies, 28, 11-20.

Hunnicut, B. K. (2013). Free time: The forgotten American dream. Philadelphia: Temple University Press.

Innis, H. (1951). The bias of communication. Toronto: University of Toronto Press.

Jacobs, J. A., \& Winslow, S. E. (2004). Overworked faculty: Job stress and family demands. The Annals of the American Academy of Political and Social Science, 596, 104-129.

Leccardi, C. (1996). Rethinking social time: Feminist perspectives. Time \& Society, 5(2), 169186.

Levine, R. (1997). A geography of time: The temporal misadventures of a social psychologist; Or how every culture keeps time just a little bit differently. New York: Basic Books.

Levy, D. M. (2007). No time to think: Reflections on information technology and contemplative scholarship. Ethics and Information Technology, 9(4), 237-49.

Linder, S. B. (1970). The harried leisure class. New York: Columbia University Press.

Manzerolle, V., and Kjøsen, A. M. (2012). The communication of capital: Digital media and the logic of acceleration. Triple C: Communication, Capitalism \& Critique, 19(2), 214-229.

Martineau, J. (2015). Time, capitalism and alienation: A socio-historical inquiry into the making of modern time. London: Brill.

Marx, K., \& Engels, F. (1969). Theses on Feuerbach. In, Marx/Engels selected works, volume 1. (W. Lough, Trans.) (pp. 13-15). Moscow: Progress Publishers. Retrieved from https:/www.marxists.org/archive/marx/works/1845/theses/engels.htm

McAdam, D. (1988). Freedom summer. New York: Oxford University Press.

McAdam, D., \& Sewell, W. H. Jr. (2001). It's about time: Temporality in the study of social movements and revolutions. In R. R. Aminzade, J. A. Goldstone, D. McAdam, E. J. Perry, 
W. H. Sewell, S. Tarrow \& C. Tilly (Eds.), Silence and voice in the study of contentious politics (pp. 89-125). Cambridge: Cambridge University Press.

Mendick, H. (2014). Social class, gender and the pace of academic life: What kind of solution is slow? Forum: Qualitative Social Research, 15(3). Retrieved from http://www.qualitativeresearch.net/index.php/fqs/issue/view/50.

Menzies, H. \& Newson, J. (2007). No time to think: Academics' life in the globally wired university. Time \& Society, 16(1), 83-98.

Menzies, H., \& Newson, J. (2008). Time, stress and intellectual engagement in academic work: Exploring gender difference. Gender, Work and Organization, 15(5), 504-522.

Müller, R. (2014). Racing for what? Anticipation and acceleration in the work and career practices of academic life science postdocs. Forum: Qualitative Social Research, 15(3). Retrieved from http://www.qualitative-research.net/index.php/fqs/issue/view/50.

Nowotny, H. (1994). Time: The modern and postmodern experience. Cambridge: Polity Press.

Odih, P. (2003). Gender, work and organization in the time/space economy of 'just-in-time' labour. Time \& Society, 12(2-3), 293-314.

Pietrzyk, K. (2013). Time, technology, and troublemakers: 'Fast activism' and the alterglobalization movement in Canada (Unpublished $\mathrm{PhD}$ dissertation). York University, Toronto, Canada.

Porter, T., \& Stockdale, L. (in press). The strategic manipulation of transnational temporalities. Globalizations, 12(5).

Postone, M. (1993). Time, labor, and social domination. Cambridge: Cambridge University Press.

Readings, B. (1996). The university in ruins. Cambridge: Harvard University Press.

Reith, G. (2004). Uncertain times: The notion of 'risk' and the development of modernity. Time \& Society, 13(2/3), 383-402.

Reynolds, D. (1997). Democracy unbound: progressive challenges to the two party system. Boston, MA: South End Press

Rifkin, J. (1987). Time wars: The primary conflict in human history. New York: H. Holt.

Rosa, H. (2003). Social acceleration: Ethical and political consequences of a desynchronized high-speed society. Constellations, 10(1), 3-33.

Rosa, H. (2005). The speed of global flows and the pace of democratic politics. New Political Science, 27(4), 445-459.

Rosa, H. (2013). Social acceleration: A new theory of modernity. (J. Trejo-Mathys, Trans.). New York: Columbia University Press.

Scheuerman, W. E. (2005). Busyness and citizenship. Social Research, 72(2), 447-470.

Schor, J. B. (1991). The overworked American: The unexpected decline of leisure. New York: Basic Books.

Schuurman, N. (2009). Work, life, and creativity among academic geographers. Progress in Human Geography, 33(3), 307-312.

Shantz, J., \& Vance, C. (2000). Fighting the neoliberal agenda in post-secondary education. Workplace, 6, 94-97.

Slaughter, S, \& Leslie, L. L. (1997). Academic capitalism. Baltimore, MD: John Hopkins University Press.

Slaughter, S., \& Rhoades, G. (2004). Academic capitalism and the new economy: Markets, state and education. Baltimore and London: Johns Hopkins University Press.

Tarrow, S. (1998). Power in movement: Social movements and contentious politics. Cambridge: Cambridge University Press.

The Economist. (2014, December 20). Why is everyone so busy? The Economist. Retrieved from http://www.economist.com/news/christmas-specials/21636612-time-poverty-problempartly-perception-and-partly-distributionwhy? fsrc $=\mathrm{scn} \% 2 \mathrm{Ftw} \% 2 \mathrm{Fte} \% 2 \mathrm{Fpe} \% 2 \mathrm{Fed} \% 2 \mathrm{~F}$ whyiseveryonesobusy

Thompson, E. P. (1967). Time, work-discipline, and industrial capitalism. Past \& Present, 38, 56-97.

Tilly, C. (2004). Social movements, 1768-2004. Boulder, CO: Paradigm Publishers.

Tomlinson, J. (2007). The culture of speed: The coming of immediacy. Los Angeles \& London: Sage. 
Vostal, F. (2015). Academic life in the fast lane: The experience of time and speed in British academia. Time \& Society, 24(1), 71-95.

Wajcman, J. (2015). Pressed for time: The acceleration of life in digital capitalism. Chicago and London: The University of Chicago Press.

Watson, A. J. (2006). Marginal man: The dark vision of Harold Innis. Toronto: University of Toronto Press.

Wolfinger, Nicholas H. (2013, July 29). For female scientists, there's no good time to have children. The Atlantic. Retrieved from

http://www.theatlantic.com/sexes/archive/2013/07/for-female-scientists-theres-no-goodtime-to-have-children/278165/

Ylijoki, O. (2013). Boundary-work between work and life in the high-speed university. Studies in Higher Education 38(2), 242-255.

Ylijoki, O. \& Mantyla, H. (2003). Conflicting time perspectives in academic work. Time \& Society 12(1), 55-78. 